\title{
THE DESCRIPTION OF NEMATODE IN Barbonymus schwanenfeldii AT KENYIR LAKE, TERENGGANU
}

\author{
N.HAFIZA ${ }^{\text {A* }}$ AND FAIZAH SHAHAROM-HARRISON ${ }^{\mathrm{B}}$ \\ ${ }^{\mathrm{a}, \mathrm{b}}$ Faculty of Fisheries and Food Science, Universiti Malaysia Terengganu, Kuala Nerus, Terengganu, Malaysia \\ "Corresponding author: fieyzakamaruddin@gmail.com
}

\begin{abstract}
Cucullanus sp. is a genus of nematode infecting Barbonymus schwanenfeldii. It is categorized under Family Cucullunidae. The genus Cucullanus $s p$ consists of various species around the world, parasitizing freshwater, brackish-water or marine fishes. Cucullanus $s p$ are mainly found in internal organs like stomach, intestine, kidney, and spleen. This parasitic organism can cause an economic impact, especially for animals with high market value, which are commercialized and used for human consumption. The objectives of this study are to study the morphological characteristics of Cucullanus $s p$ and to identify genus of Cucullanus $s p$ which are found on tinfoil barb, Barbonymus schwanenfeldii at Kenyir Lake, Terengganu. There is not enough data on Cucullanus sp on $B$. schwanenfeldii. Six samples of tinfoil barb were collected at Kenyir Lake from 25 to 27 October 2018. Each sample of fish was measured and recorded for length and weight using ruler and weighing balance respectively. The fish were examined at camping site at Lawit Resort, Kenyir Lake. The nematode species found were brought back to Health of Aquatic Organism laboratory. The abdominal and gastrointestinal tracts of the fishes were dissected and placed in petri dishes. The nematodes found were collected and observed under the dissecting microscope. The nematode specimen was placed on a glass slide with a drop of lactophenol and observed under the compound microscope fitted with dino-eye. The sample was later fixed with $70 \%$ alcohol. The morphological characteristic was drawn using camera lucida fitted to a compound microscope. (40X magnification). The picture of nematode was captured by using Advanced Research Microscope (Nikon Eclipse 80i) and measurements of the nematode was also made. Hence, the nematode found was identified as male Cucullanus sp.
\end{abstract}

Keywords: Nematode parasite, Barbonymus schwanenfeldii, Tinfoil barb, Cucullanus sp, Tasik Kenyir

\section{Introduction}

Nematodes are a large group of rounds, threadlike worms either free-living organisms or parasitic species. Nematode parasites are relatively long worms, smooth and cylindrical which are found in marine or freshwater wild fish and found in the digestive tract of fish which is the definitive host (Yanong, 2002; Bamidele, 2016; Petter \& Le-Bel, 1992). The nematodes, essentially, are biohelminths which either complete their development in fish or spend parts of their developmental stages in fish. The nematode eggs or larvae are passed into the water with the faeces of fishes. They are eaten by various invertebrates, which are eaten by fish which become infected. When the final host is a predatory fish or piscivorous bird or mammal, another intermediate host, usually also a fish, is introduced into the life cycle. Nematodes generally lack body colour, being transparent or with a whitish or yellowish tinted cuticle (Moravec, 1994). The nematode body is covered with a strong protecting cuticle that is flexible but does not stretch (Kabata.1985). The cuticle usually has fine transverse striations or spines on its free margins. They maintain their shape by turgidity imparted by the fluid filing in the body cavity (Kabata, 1985). Nematodes have a simple body cavity with a cylindrical intestine which terminates in an anal orifice located ventrally (Amlacher, 1970). Their form of shape can be used to distinguish them easily from other worm groups (Yamaguti, 1961). 
Recently, many studies have been done on nematodes in the Southeast Asian countries such as Rhabdochona sp. (Moravec \& Yooyen, 2011), Cucullanus sp. (Yooyen et al., 2011), Spinitectus sp. (Purivirojkul, 2009), Spinitectus sp. (Moravec et al., 2004) in South Asian countries. The studies are mainly describing their characteristics, (Moravec et al, 2004) recording new data on morphology and systemic status of Spinitectus sp. in central China. Yooyen et al., (2011) described a new species of Cucullanus $s p$. from marine fishes of Thailand. Recently, new species of Rhabdochona sp had been found from freshwater fishes in Thailand (Moravec \& Yooyen, 2011).

However, not many studies have been done on freshwater fish nematodes in Malaysia. In Lake Kenyir, high abundance of nematodes has been found in some fishes such as Cyclocheilichthys apogon, Chitala chitala, Channa micropeltes and Barbonymus schwanenfeldii.

The most important taxonomic features are the head and tail such as lip around the mouth, the oesophagus, and pharynx. The mouth is an unarmed opening surrounded by two, three, four or six lips, and known as labia (Kabata, 1985). The primitive species of nematodes have six lips. In some nematodes, cuticular lobes arise and replace the labia and they are pseudobalia. The anterior part of nematodes includes mouth, pharynx and esophagus which are a gradular or muscular esophagus. Moreover, in some nematodes, the anterior part of the mouth expands into the buccal capsule.

The intestine of nematodes is a straight tube and is a complete digestive system. The posterior end of the male and female nematode is different where the male is often flexed ventrally or coiled in a tight spiral. The sexes are separated, each having an individual male and female genital system. Commonly, the female is bigger than the male. An adult male has spicules near the tail end (Moller, et al., 1986).

For the species identification, the important parts include the head and tail as well as the genital organs. The important parts of genital organs are genital pore in the female and its distance from the posterior and anterior end of the body, also the host and location where the nematodes are found (Lucky,1977).

\section{Materials and Methods}

\section{Sampling}

The samples of tinfoil barb (Barbonymus schwanenfeldii) were caught by using gill net in Lake Kenyir. Six samples of fish were caught. The fish samples were examined at Lawit Resort during Fish Parasitology field trip. The nematode species found were transferred into the bijou bottle and brought back to the MKOA laboratory for detailed observation.

\section{Examination of fish}

The live fish were kept in the same water from where they were caught. The fish were measured in length and weight using measuring board and electronic scale. The weight of fish was taken and the length was measured for total length and standard length. For standard length, the fish was measured starting from protruding upper jaw until caudal peduncle while for the total length, the fish was measured from protruding upper jaw until the tail. All the data were recorded. Then, the fish was killed by pithing method where the central nervous system of the fish was cut using a sharp scalpel or a pair of sharp scissors.

\section{Endoparasite Examination}

The fish was cut from the anus through to the abdominal muscle with a pair of scissors but avoiding cutting the alimentary system. Then, a cut was made toward operculum along the lateral line and an incision made downward until the chest, after reaching the operculum. During the cutting process, the abdomen had to be lifted to avoid damage or rapture to the internal organs. Secondly, the stomach and intestine were observed directly after dissection. Then, the internal organs were placed on the petri dish and covered with saline water to be observed under the dissecting microscope.

Next, the stomach and intestine were examined individually in the petri dish respectively to find the parasite. After that, the samples were observed under the dissecting microscope.

Lastly, the stomach and intestine were cut open by using a pair of scissors. The small pieces of intestine were pressed on the glass slide then covered it with cover slip. The part of organs 
was observed under the compound microscope using the 10x, and 40x magnification. The parasite (nematode) found was recorded.

\section{Fixing method}

Fixing is commonly used for preserving and storing parasite. A pipette was used to keep the nematode in $70 \%$ alcohol in a bijou bottle. For examination, the nematode was taken out and put on a glass slide then a drop of lactophenol was added on the glass slide and covered with the cover slip. It was examined under the microscope. Then, the nematode was fixed and placed in the bijou bottle with $70 \%$ alcohol.

\section{Capture the image of nematode}

The sample was examined under the dissecting microscope then the image was captured using the dino-eye fitted to the compound microscope. After that, the specimen was observed, and images captured using Advanced Research Compound Microscope (Nikon Eclipse 80i).

\section{Drawing and measurement of parasite}

The drawings of nematode were carried out using camera lucida fitted to the Compound Microscope. The scale bar in the ocular objective was drawn on the drawing and was later calibrated in order to give the measurement of nematode in micronmeter.

\section{Results}

Table 1: The measurement of nematode, Cucullanus sp.

\begin{tabular}{|c|c|c|c|}
\hline Component & Variable & Measurements $(\mu m)$ & Magnification \\
\hline Whole Body & Length, $a_{1}$ & 4148.90 & $10 X$ \\
\hline Head & $\begin{array}{c}\text { Length, } b_{1} \\
\text { Thickness, } b_{2}\end{array}$ & $\begin{array}{l}546.30 \\
154.68\end{array}$ & $\begin{array}{l}40 X \\
40 X\end{array}$ \\
\hline Oesophagus & $\begin{array}{c}\text { Length, } c_{1} \\
\text { Thickness, } c_{2}\end{array}$ & $\begin{array}{l}212.96 \\
87.96\end{array}$ & $\begin{array}{l}40 X \\
40 X\end{array}$ \\
\hline \multicolumn{4}{|l|}{ Cephalic head: } \\
\hline $\begin{array}{l}\text { Head Papilla } \\
\text { Head Papilla } \\
\text { Head Papilla } \\
\text { Head Papilla }\end{array}$ & $\begin{array}{l}\text { Length, } d_{1} \\
\text { Length, } d_{2} \\
\text { Length, } d_{3} \\
\text { Length, } d_{4}\end{array}$ & $\begin{array}{l}5.56 \\
4.63 \\
4.63 \\
5.56\end{array}$ & $\begin{array}{l}40 X \\
40 X \\
40 X \\
40 X\end{array}$ \\
\hline \multicolumn{4}{|l|}{ Lip of papilla: } \\
\hline $\begin{array}{l}1 \\
2 \\
3 \\
4\end{array}$ & $\begin{array}{l}\text { Thickness, } e_{1} \\
\text { Thickness, } \mathrm{e}_{2} \\
\text { Thickness, } \mathrm{e}_{3} \\
\text { Thickness, } \mathrm{e}_{4}\end{array}$ & $\begin{array}{l}2.78 \\
2.78 \\
2.78 \\
2.78\end{array}$ & $\begin{array}{rr} & 40 X \\
& 40 X \\
40 X \\
40 X\end{array}$ \\
\hline $\begin{array}{c}\text { Base of papilla: } \\
1 \\
2 \\
3 \\
4\end{array}$ & $\begin{array}{l}\text { Thickness, } \mathbf{f}_{1} \\
\text { Thickness, } \mathbf{f}_{2} \\
\text { Thickness, } \mathbf{f}_{3} \\
\text { Thickness, } \mathbf{f}_{4}\end{array}$ & $\begin{array}{l}4.63 \\
4.63 \\
4.63 \\
4.63\end{array}$ & $\begin{array}{l}40 X \\
40 X \\
40 X \\
40 X\end{array}$ \\
\hline $\begin{array}{l}\text { Tail } \\
\text { Papilla of tail } \\
\text { Papilla of tail } \\
\text { Papilla of tail } \\
\text { Papilla of tail }\end{array}$ & $\begin{array}{l}\text { Length, g } \\
\text { Length, } g_{1} \\
\text { Length, } g_{2} \\
\text { Length, } g_{3} \\
\text { Length, } g_{4}\end{array}$ & \begin{tabular}{|l|l|}
706.48 \\
17.59 \\
16.67 \\
17.59 \\
21.30
\end{tabular} & $\begin{array}{l}40 X \\
40 X \\
40 X \\
40 X \\
40 X\end{array}$ \\
\hline Gubernaculum & Length, h & 85.19 & $40 X$ \\
\hline
\end{tabular}




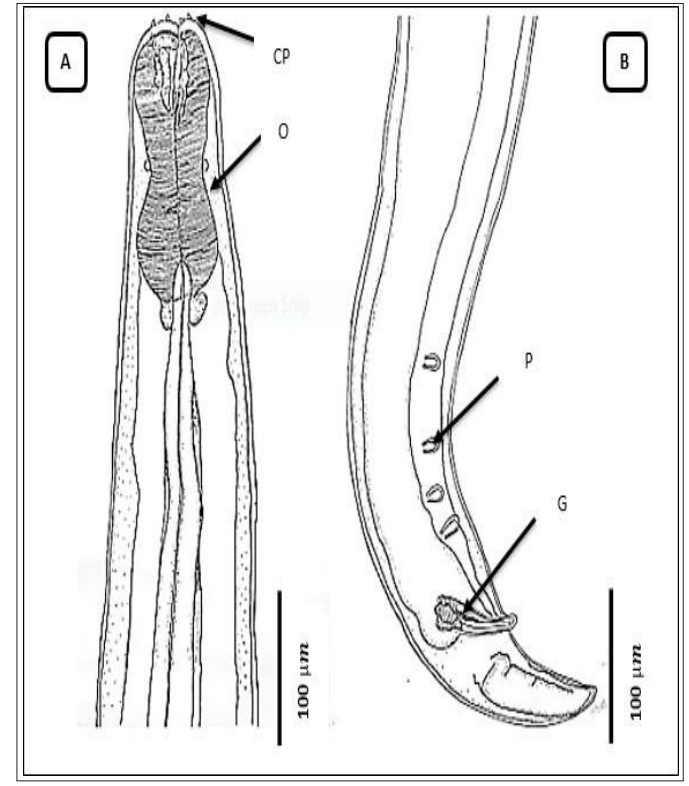

Figure 1: Drawing of male Cucullanus sp. which was carried out using camera lucida fitted to the Compound Microscope. (A) The anterior of male Cucullanus sp. (B) The posterior of male Cucullanus sp. Abbreviated indicators, $\mathrm{cp}=$ cephalic papilla; $\mathrm{o}=$ oesophagus; $\mathrm{p}=$ papil
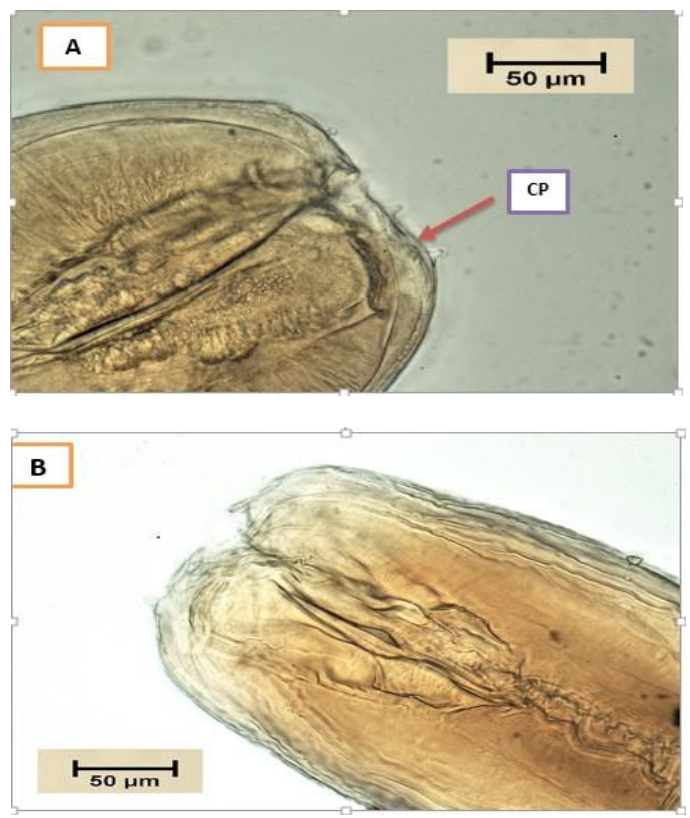
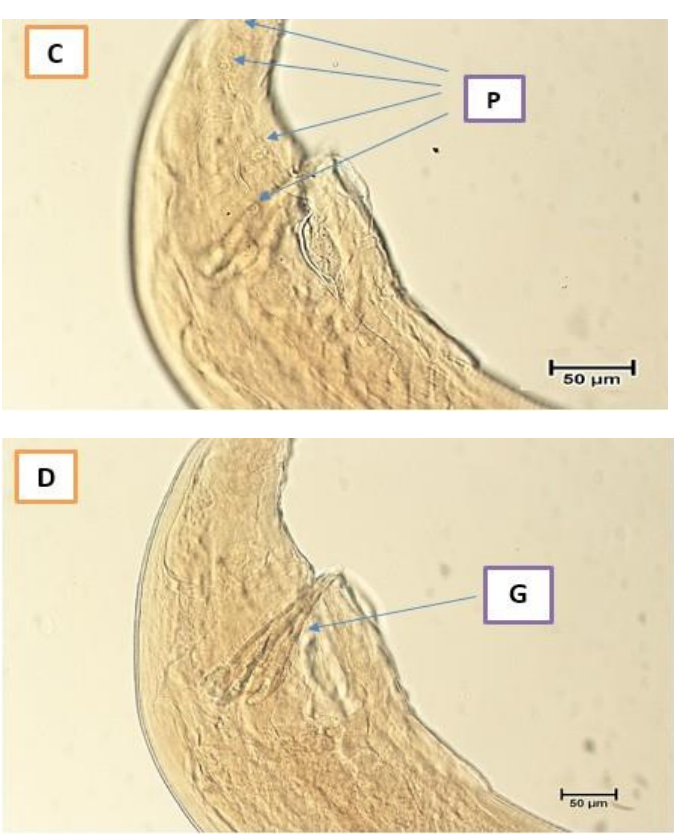

Figure (A), Figure (B), Figure (C), and Figure (D): Picture of male Cucullanus sp. under Advanced Research Compound Microscope (Nikon Eclipse 80i) with 40X Magnification. (A) CP-cephalic papilla, (B) nematode head, (C) PPapillae end of tail, and (D) G- gubernaculum.

Description: The nematode has a slender body of length 4148.90 with a thick cuticle. The size of the nematode is small, and the colour of the parasite is whitish. Four papillae were visible at the nematode mouth opening. The head of the nematode had a buccal cavity opening into a club-shaped oesophagus. At the anterior end of the oesophagus, the two ends of nerve ring were visible clearly using camera lucida.

\section{Discussion}

According to Idress Mailoud (2017), the nematode found was Cucullanus sp. in $B$. schwanenfeldii at Kenyir Lake. The Cucullanus sp. that was described by him was larger than the parasite in this present study. The main feature of this parasite was the presence of the nerve ring at the anterior end. The parasite found was a male species where the gubernaculum could be clearly seen under Research Advanced 
Compound Microscope (Nikon Eclipse 80i). The identification of the Cucullanus sp. by Idress Mailoud, 2017 has been confirmed by Professor Robin Overstreet from Florida University.

In addition, species of nematode that found in gastrointestinal tract $B$. schwanenfeldii at Kenyir Lake, Terengganu (Surzanne et al., 2014) is Cucullanus sp. under Family Cucullanidae. According to Suzarnne et al, 2014, the nematode genus Cucullanus has a mouth perpendicular to the body axis, the absence of an intestinal caecum, and the presence of sclerotized plaques in the pseudo buccal capsule with a Y-shaped sature. They also reported that the female Cucullanus sp. is bigger than the male Cucullanus sp. Timi and Lanfran (2006) identified the species of nematode based on the length and shape of the spicules on the position of the excretory pore, number and arrangement of caudal papillae. From this study, the male nematode has a gubernaculum which can be seen clearly through the images that was captured under Advanced Research Microscope (Nikon Eclipse 80i).

\section{Conclusion}

This study has found one male nematode in Barbonymus schwanenfeldii and has been identified as a Cucullanus sp. and under Family Cucullanidae. The morphological characteristics of this parasite have been described such as the club-shaped oesophagus encircled by the nerve ring. Other than that, the parasite has also been described by having four cephalic papillae on the rounded head. The presence of the gubernaculum confirmed that the species of the nematode was a male nematode. The important structural features of the nematode were drawn using camera lucida fitted to a compound microscope and images captured under Research Advanced Compound Microscope (Nikon Eclipse 80i).

\section{Acknowledgements}

I would like to thank God for giving His blessing to complete this research successfully. I would like to express special thanks sincere gratitude to my supervisor, Prof Emeritus Dr. Faizah binti Sharoum and all the laboratory staff at MKOA for giving me the opportunity to work on this project.

\section{References}

Amlacher, E. (1970). Textbook of Fish Diseases. (Translated by Conroy D. A. \&Herman, R. L.), T.F.H. Publications, USA: Neptune City, New Jersey.

Bamidele, A. (2016). Studies on Cucullanus sp. (Nematode: Cucullanidae) parasitic in Tilapia zillii (Gervais, 1848) from Lekki Lagoon, Lagos, Nigeria. Journal of Aquatic Biology and Fish, 20(2), 79-87.

Idress Mailoud (2017). Heavy Metals in Cucullanus sp. (Nematoda) in Relation to its host, and the environment of Kenyir Lake, Malaysia. Doctor of Philosophy Thesis, Universiti Malaysia Terengganu $140 \mathrm{p}$.

Kabata, Z. (1985). Parasites and Disease of Fish Cultured in the Tropics. London: Taylor and Francis Ltd.318p.

Lucky, Z. (1977). Methods for the Diagnosis of Fish Disease. Franklin Book Programs Inc., Cairo. Translated from Czechoslovakian by Dr. Glenn I., Hoffman. 140p.

Moller, H. \& Anders, K. (1986). Diseases and parasites of Marine fishes. Kiel: Moller.365pp.

Moravec, F. (1972). Studies on the development of the nematode Rhabdochona (filichona) ergensi Moravec, 1968. Folia Parasites, 19, 321-333.

Moravec, F. (1984). General aspects of the bionomics of the parasitic nematodes of freshwater fishes. Prague Czechoslovakia: Academia studie VSAV, 4, 114 pp.

Moravec, F. (1994). Parasitic Nematodes of Freshwater Fishes in Europe. Kluwer Academic Publisher, The Netherlands. $473 p$. 
Moravec, F., Nie, P., \& Wang G. (2004). New data on the morphology and systematic status of Spinitectus petrowi and Spinitectus gigi (Nematoda: Cystidicolidae) parasitic in catfishes in central China. Folia Parasitol, 51: 339-351.

Moravec, F. (2007). Nematode parasites of fishes: recent advances and problems of their research. Parassitologia, 49(3), 155160 .

Moravec, F., \& Yooyen T. (2011). Two new species of Rhabdochona (Nematoda: Rhabdochonidae) from freshwater fishes in Thailand. Folia Parasitol (Praha). 58(3): 2432.Pacific eels (Anguilla spp.). Journal of Parasitology, 52, 343-348.

Petter, A. J. \& Le-Bel, J. (1992). Two new species in the genus Cucullanus (Nematoda: Cucullanidae) from the Australian region. Institute of Oswaldo Cruz, 87, 201-206.

Purivirojkul, W. (2009). Fish parasite diversity in the Mekong River in the north of Thailand. KKU Science Journal. 37 (Suppl.): 62-70.
Surzanne, M. A., Hidayah, N. Z., Wahidah, W., Ihwan, M. Z. \& Marina, H. (2014). Morphological Study of Cucullanus sp. (Cucullanidae, Seuratoidea) Parasitic in Barbonymus schwanenfeldii (Tinfoil Barb, Lampam Sungai) in Kenyir Lake, Terengganu. Terengganu, Malaysia: University of Terengganu.

Timi, J. T.,Lanfranchi,A. L. (2006).Anew species of Cucullanus (Nematoda: Cucullanidae) parasitizing Conger orbignianus (Pisces: Congridae) from Argentinean waters. Journal of Parasitology, 92, 151-154.

Yamaguti, S. (1961). Systema Helminthum vol. (iii). The Nematode Vertebrates Part 1 and 11. Interscience. Publisher, 1-1261 pp.

Yooyen, T., Moravec, F., \& Wongsawad C. (2011). Two new sibling species of Procamallanus (Spirocamallanus) (Nematoda: Camallanidae) from marine fishes in the Gulf of Thailand. J. Parasitol. 97: 931-938.

Yanong, R. P. E., (2002). Nematode (Roundworm) Infection in Fish. Galesville: Institute of Food and Agricultural Sciences. The University of Florida. 